\title{
A indústria do Fitness, a mercantilização das práticas corporais e o trabalho do professor de Educação Física: o caso Body Systems
}

\author{
Ingrid Rodrigues Gomes* \\ Regiane de Avila Chagas** \\ Fernando Mascarenhas***
}

\begin{abstract}
Resumo: Esta pesquisa busca analisar os processos de gestão e tendências de inovação inerentes ao desenvolvimento da "Indústria do Fitness", com especial atenção para o sistema de franquias, bem como avaliar as implicações deste sistema para o trabalho do professor de educação física. Organizase a partir de revisão bibliográfica, pesquisa documental e pesquisa de campo fundados no estudo do sistema propagado pela Body Systems, que envolve a racionalização e a padronização das técnicas de produção e distribuição de programas de ginástica de grupo. Conclui que o sistema impacta a organização do trabalho interno às academias, tanto na forma de comercialização como na concepção de um novo modelo de gestão, desqualificando a atividade do professor de educação física.
\end{abstract}

Palavras-chave: Educação Física. Academias de ginástica. Gerenciamento da Prática Profissional. Trabalho.

\footnotetext{
*Licenciada em Educação Física. Professora da SEE-GO. Integrante do Grupo de Estudo e Pesquisa em Esporte, Lazer e Comunicação da UFG. Goiânia, GO, Brasil. E-mail: anjo_ind@hotmail.com.

**Mestre em Educação. Professora da FEF-UFG. Professora da SEE-GO. Integrante do Grupo de Pesquisa em Formação e Profissionalização Docente da UFG. Goiânia, GO, Brasil E-mail: regianeavila@yahoo.com.br.

***Doutor em Educação Física. Professor da FEF-UnB. Integrante do Grupo de Estudo e Pesquisa em Esporte, Lazer e Comunicação da UFG. Coordenador do Grupo de Pesquisa e Formação Sociocrítica em Educação Física, Esporte e Lazer da UnB. Brasília, DF, Brasil. Email: fernandom@unb.br.
} 


\section{INTRODUÇÃO}

A Body Systems é uma empresa que comercializa no Brasil e América Latina um sistema de mesmo nome que engloba programas de ginástica de grupo pré-coreografada, produzidos e distribuídos desde 1968 pela rede neozelandesa de academias Les Mills. Ante a constatação do valor de troca e alta liquidez de seus programas, a partir da década de 1980, através da franqueadora Les Mills International, a rede inaugurou o seu processo de internacionalização. A expansão da Les Mills se evidencia pelos números. São 10.500 academias franqueadas em mais de 50 países, atingindo um público de mais de 4 milhões de consumidores. Presente no mercado brasileiro desde 1997, representada pela Body Systems Latin America, a Les Mills conta com mais de 500 academias franqueadas e 2.000 professores credenciados. Na América Latina, totaliza uma rede de 2.200 academias, com 8.000 professores e público acima de 1 milhão de consumidores ${ }^{1}$.

Todos os programas distribuídos pela Les Mills são produzidos em Auckland, Nova Zelândia, e sua concepção une coreografias de baixo nível de complexidade, sob o aspecto da execução, e com músicas altamente estimulantes, dando forma a aulas excitantes e de rápida frequência. A cada período de três meses, são agregadas a cada um destes programas novas aulas, com músicas, instruções e coreografias reproduzidas em mídias que permitem sua distribuição em escala mundial. Assim, a Les Mills padroniza e massifica, por uma vasta rede de academias, as mesmas aulas e coreografias. Tal processo, de acordo com Ortiz (1994), segue a lógica mais geral de mundialização da cultura, envolvendo a produção e distribuição de mercadorias globais, um conjunto de produtos e serviços destituídos de vínculo territorial, distribuídos por grupos multinacionais e livres de todo e qualquer tipo de restrição cultural.

Abordando diferentes aspectos, outras iniciativas de estudo sobre o Body Systems já foram desenvolvidas no campo da Educação

${ }^{1}$ Números obtidos a partir do website da Les Mills Internacional. Disponível em: http:// www.lesmills.com. Acesso em: 5 mar. 2008.

Movimento, Porto Alegre, v. 16, n. 04, p. 169-189, outubro/dezembro de 2010. 
Física (BRAUNER, 2007; MOURA et al., 2007; TOLEDO; PIRES, 2008). Nosso propósito, a partir da análise do sistema propagado pela Les Mills e Body Systems, que envolve a racionalização e a padronização das técnicas de produção e distribuição de programas de ginástica de grupo, é o de identificar e avaliar os processos de gestão e tendências de inovação inerentes ao desenvolvimento da Indústria do Fitness no Brasil², com especial atenção para o sistema de franquias e sua relação com o mapa da divisão internacional do trabalho, bem como avaliar as implicações deste sistema para a organização do trabalho do professor de Educação Física nas academias de ginástica.

\section{DeLINEAMENTO DO ESTUDO}

A pesquisa pode ser caracterizada como um estudo de caso, pois através do princípio da verificação de um sistema particular e real de desenvolvimento, o Body Systems, busca confrontar e examinar a gestão, a organização do trabalho e as tendências de inovação já evidenciadas pela Indústria do Fitness em escala global. No que diz respeito a base operacional, o estudo combina as técnicas de análise documental, observação de campo e entrevista, conferindo ao trabalho uma abordagem qualitativa. Partiu-se da descrição e interpretação do sistema Body Systems, por intermédio da pesquisa junto aos websites institucionais da Les Mills Internacional, da Body Systems Latin America e da Body Systems no Brasil. Foram utilizadas, complementarmente, outras fontes documentais, materiais impressos, DVD's e CD's de instrução e capacitação de professores, programas de prescrição etc. Por um lado, os documentos oficiais são considerados como fontes enviesadas, por apresentarem um retrato irrealista de como funcionam as instituições ou, neste caso, a empresa Body Systems. Contudo, nosso interesse nesse tipo de informação se justificou porque tais documentos carregam a

${ }^{2} A$ noção de Indústria do Fitness, vinculada ao processo de produção e distribuição das práticas corporais nas academias de ginástica, é desdobrada aqui do conceito de Indústria Cultural (ADORNO; HORKHEIMER, 1985), vinculada ao processo mais geral de padronização e racionalização das técnicas de produção e distribuição dos bens e serviços culturais mercantilizados.

Movimento, Porto Alegre, v. 16, n. 04, p. 169-189, outubro/dezembro de 2010. 
propriedade de oferecer elementos para a compreensão de como o sistema divulga sua proposta (BOGDAN; BIKLEN, 1994).

Além da perspectiva da empresa, buscamos conhecer a experiência de formação de seus professores. Para esse fim, a pesquisa de campo envolveu a observação e entrevista junto a participantes e professores do Curso de Body Vive na $5^{\circ}$ Convenção Saúde Sport e Fitness, em março de 2008, na cidade de Goiânia$\mathrm{GO}^{3}$. A observação nos permitiu uma visão mais concreta do objeto. De acordo com Severino (2007, p. 123), na pesquisa de campo "[...] a coleta de dados é feita nas condições naturais em que os fenômenos ocorrem, sendo assim diretamente observados, sem intervenção ou manuseio por parte do pesquisador". Conforme as orientações de Bogdan e Biklen (1994), nossa observação foi registrada na forma de notas de campo. Acrescente-se que, para além da observação, coletamos informações através de entrevistas, que forneceram dados adicionais para o exame do nosso objeto de investigação.

Sendo assim, apresentamos as reflexões e conclusões geradas a partir desta pesquisa, evidenciando os desdobramentos e nuances que envolvem a subordinação das práticas corporais a forma mercadoria e o trabalho do professor de Educação Física em academias de ginástica.

\section{A franduia Val À ACADEMIA}

A Body Systems Latin America, sediada na cidade de São Paulo, é uma empresa franqueadora que comercializa no Brasil e América Latina programas de ginástica de grupo produzidos e distribuídos no mercado mundial de academias pela Les Mills International. Os programas da Body Systems são desenvolvidos em articulação com um método de treinamento profissional voltado aos seus instrutores, o Body Training Systems. A partir do estudo

${ }^{3}$ Foram entrevistados cinco participantes do curso e três professores, os Treinadores-Pro, sendo um destes o gerente comercial da Body Systems na região centro-oeste, que tem sede em Brasília, e os outros treinadores que ministraram o curso de Body Vive. Destaca-se que todos participaram da investigação com livre e esclarecido consentimento.

Movimento, Porto Alegre, v. 16, n. 04, p. 169-189, outubro/dezembro de 2010. 
junto a fontes como os DVD's e CD's que integram este treinamento, bem como das páginas web da Les Mills e da Body Systems, sistematizamos um conjunto de dados que possibilitam uma compreensão geral do sistema.

Organizada a partir do sistema de franquias ${ }^{4}$, a Body Systems investe nas novas tecnologias de informação e comunicação para a distribuição de seus produtos e serviços, utilizando a internet, mídias de áudio, vídeo e linhas especiais de tele-atendimento, além de material impresso promocional de alta qualidade gráfica. Trata-se de um conjunto de recursos integrados que mobilizam seu processo de negócios. Promove ainda, com fins de suporte para as academias franqueadas, encontros presenciais de consultoria aos seus gestores e funcionários, enfocando temas como marketing, atendimento ao cliente, vendas etc. Mas a grande referência de comunicação e relacionamento das franqueadas com a Body Systems é seu website, com abundância de informações e variada oferta de produtos e serviços.

Em seu website, a título de exemplo, podem ser identificadas todas as academias franqueadas no Brasil, localizadas por cidade e bairro, com a seleção dos programas ofertados por cada uma delas. Estão igualmente disponíveis para as academias informações sobre os professores credenciados pelo sistema, com sua respectiva qualificação e indicação dos programas para os quais estão autorizados a trabalhar. Do mesmo modo, são indicados para o professor que queira se tornar um instrutor do sistema os procedimentos para sua capacitação, avaliação e credenciamento. Para tal, há divulgação atualizada do calendário de treinamentos promovidos pela Body Training Systems, que envolve cursos de iniciação ao fitness, cursos modulares de capacitação para os

4"Uma franquia empresarial é um sistema pelo qual um franqueador sede ao franqueado o direito de uso da marca ou patente, associado ao direito de distribuição exclusiva ou semiexclusiva de produtos ou serviços e, eventualmente também ao direito de uso de tecnologia de implantação e administração do negócio ou sistema operacional desenvolvidos ou detidos pelo franqueador mediante a remuneração direta ou indireta". Extrato correspondente ao Art. 20 da Lei no 8.955, de 15 de dezembro de 1994. Disponível em: http://www.planalto.gov.br/CCIVIL/ Leis/L8955.htm. Acesso em: 1 fev. 2008.

Movimento, Porto Alegre, v. 16, n. 04, p. 169-189, outubro/dezembro de 2010. 
programas, workshops trimestrais, convenções, aulas especiais, palestras etc.

A comunicação pela web possibilita ainda acesso aos agentes comerciais, promoções e parceiros da empresa. As primeiras instruções são explicativas, referentes a decisão sobre os programas a serem implantados, ao valores relativos a adesão e os termos do contrato. Uma vez contratada a franquia, além da marca Body Systems e ao valor simbólico a ela agregado, a academia franqueada tem acesso aos seguintes produtos e serviços:

Kit enviado por sedex após a assinatura do contrato contendo: manual do proprietário, placa de estabelecimento licenciado, pôsteres dos programas licenciados, CD-ROM com logos e imagens dos programas, material para divulgação em mala direta e para impressão de convites para a aula; cartazes de lançamentos dos novos mixes a cada WS; nome da academia em nosso website; consultores (via telefone): análise de quadro de horários, análise de preços/planos, estratégias de marketing e vendas, e todo o suporte que sua academia precisar; assessoria em comunicação visual: criação do layout de fachadas, outdoors, banners, folders, etc.; assessoria jurídica; participação em campanhas cooperadas de marketing com parceiros como revista Boa Forma e kellog's; cursos na área técnica e administrativa como Top Manager, GFM (Group Ftiness Management) etc., disponíveis em alguns de nossos workshops trimestrais para toda a equipe da academia $^{5}$. (Disponível em: www.lesmills.com).

Tendo definido os programas a serem implantados, passo a passo, o franqueado deve escolher os professores que serão treinados, apresentar o sistema em reunião com os funcionários, entrar em contato via Central de Atendimentos para agendar o treinamento inicial e divulgar o programa junto a sua clientela. Com avaliação e acompanhamento de todo o processo de implantação da franquia, a

${ }^{5}$ Informações retiradas do website da Les Mills. Disponível em: www.lesmills.com. Acesso em 4 mar. 2008.

Movimento, Porto Alegre, v. 16, n. 04, p. 169-189, outubro/dezembro de 2010. 
Body Systems promete às academias mão-de-obra qualificada, além de rentabilidade e segurança de investimento. Os princípios e diretrizes que lhe permitem afirmar a eficiência do sistema estão ligados aos procedimentos gerenciais da academia, o treinamento profissional que permite um novo padrão de relacionamento com o cliente, a mudança de comportamento entre os funcionários, a praticidade na substituição dos professores, o marketing que envolve a marca Body Systens e o suporte técnico gerencial.

Esse é o contexto ao qual estão inseridas as academias de ginástica atualmente. As mais desenvolvidas possuem influências ainda mais fortes da acumulação flexível que as demais. [...] Assim sendo, a academia funciona em uma dinâmica caracterizada pela flexibilidade, pela diversificação de sua produção, pelo "foco no cliente" e, conseqüentemente, pela mudança do perfil do professor que nela trabalha. A grande academia, acompanhando uma característica do toyotismo, disponibiliza atualmente uma diversidade muito grande de aulas. Além disso, permite ao aluno ficar bastante a vontade dentro da academia, para escolher qual modalidade pretende praticar em cada dia. Nas aulas de ginástica não existem mais turmas preestabelecidas, em horários predeterminados. As turmas são montadas no momento da aula com os alunos que têm interesse em participar daquela atividade. (FURTADO, 2007, p. 311).

O modelo de acumulação flexível, segundo Harvey (1998) e Heloani (2003), se caracteriza pela flexibilidade dos processos de trabalho, produtos e padrões de consumo, reestruturação produtiva, mercadorização de bens culturais, fusões empresariais, centralização de capitais, privatizações de empresas e globalização de mercados. Tais ações permitem dinamizar as transações econômicas. Assim, em conformidade com a lógica de desenvolvimento do capital, o processo de expansão da Body Systems, impulsionado pelo sistema de franquias, expressa a formação de um grande conglomerado que, pela força dos investimentos em inovação e marketing da franqueadora, reforça a tendência monopolista decorrente das

Movimento, Porto Alegre, v. 16, n. 04, p. 169-189, outubro/dezembro de 2010. 
disputas concorrenciais inerentes ao mercado do fitness ${ }^{6}$. Na concepção de uma nova modalidade de comércio, o sistema de franquias abole os métodos tradicionais de organização do trabalho, propagando modernas técnicas de gestão junto ao setor das academias de ginástica (PINHEIRO; PINHEIRO, 2006). Enfim, o sistema e as práticas comerciais implantados pela Les Mills e sua subsidiária Body Systems abarcam uma grande cadeia de negócios, com profundos desdobramentos para o trabalho do professor de Educação Física e enorme impacto sobre a oferta dos serviços ligados a cultura corporal, sobretudo da ginástica.

\section{GinÁSTICA dESCARTÁVEL}

Os programas produzidos e distribuídos internacionalmente pela Les Mills, somados aos lançados nacionalmente pela Body Systems, possuem características que lhes identificam a um perfil de consumidor correspondente, quais sejam: Bodystep - Atividade cardiovascular desenvolvida com a utilização das plataformas conhecidas mundialmente como steps. Voltado ao segmento feminino motivado para uma aula ágil e dinâmica; Bodyjam - Uma mistura de movimentos de vários estilos como Funk, Groove, Ritmos Latinos, Caribenhos, Street Dance, Techno, Hip-Hop, Disco e Jazz-Broadway. Voltado ao segmento de jovens e adultos que gostam de dançar e buscam oportunidades de sociabilidade; Bodybalance - Condicionamento postural que utiliza movimentos adaptados de disciplinas orientais, como o Tai-chi-Chuan e Yoga e também de disciplinas ocidentais como, o Pilates. Voltado ao segmento que gosta de aulas tranqüilas e relaxantes, dirigidas a interiorização; Bodyattack Combina exercícios aeróbicos de alta intensidade com trabalhos de força e estabilização. Voltado ao segmento que gosta de treinar forte, geralmente alunos de musculação, pois exige pouca coordenação, com movimentos simples e de fácil execução; Bodycombat Baseado nas mais variadas artes marciais, pretende desenvolver a técnica dos golpes simultaneamente ao treinamento físico de todo o

${ }^{6} U \mathrm{~m}$ estudo específico sobre os aspectos que envolvem a estratégia de marketing da Body Systems, pode ser localizado em Toledo e Pires (2008).

Movimento, Porto Alegre, v. 16, n. 04, p. 169-189, outubro/dezembro de 2010. 
corpo. Voltado ao segmento que dá muitíssima importância para as técnicas, geralmente quem já treina ou atletas; Bodypump Treinamento com pesos sincronizados a músicas do momento, que visa desenvolver a força, a resistência muscular, além de melhorar a postura corporal e promover a prevenção contra a osteoporose. Voltado ao segmento masculino interessado em hipertrofia e que já treina, suscetível a discursos desafiadores que atinjam a personalidade masculina; RPM - Programa de ciclismo indoor que visa o desenvolvimento da capacidade cardiovascular. Voltado ao segmento que gosta de esportes de aventura, podendo ser alunos iniciantes ou treinados; Power Jump - Ginástica em grupo que utiliza o minitrampolim como equipamento para realizar o trabalho cardiovascular. Voltado ao segmento de jovens e adultos que buscam aliviar o estresse através da ginástica; Power Pool - Programa de condicionamento físico realizado com os alunos na piscina. Voltado ao segmento jovem ou adulto que gostam de treinar e se divertir na água?

A produção de tais programas envolve uma equipe multiprofissional num trabalho de segmentação, unificação e organização de sequiências e técnicas de ginástica com variados objetivos, conteúdos e métodos. Somente depois de submetido a um conjunto de testes para a certificação de sua qualidade e segurança, é que é liberado para distribuição. Os programas constituem cada qual um mix de CDs e DVDs com a gravação das aulas précoreografadas em áudio e vídeo. Trata-se de uma tecnologia que apresenta seqüencialmente toda a coreografia de uma aula, os objetivos relacionados a cada música, movimentos a serem realizados, tempo, número de repetições e indicações a serem dadas pelo professor. Ocorre que a cada três meses, os programas são renovados e um novo mix é lançado, o que gera dependência por parte das academias e dos professores para a atualização do padrão de qualidade Body Systems. Deste modo, com sua proposta anunciada como revolucionária e inovadora, os programas mudam permanentemente, mas apenas sob o ponto de vista de sua forma

${ }^{7}$ Informações compiladas a partir do website da Body Systems Latin America. Disponível em: http://www.bodysystems.net/. Acesso em 2 jun. 2008.

Movimento, Porto Alegre, v. 16, n. 04, p. 169-189, outubro/dezembro de 2010. 
coreográfica e invólucro estético, com a adaptação a novas músicas e ritmos.

A inovação dos programas segue a tendência apontada por Haug (1997) de obsolescência planejada das mercadorias, baseada na novidade e consequente redução do ciclo de vida das práticas ofertadas mediante o lançamento de novos mixes, com coreografias e aparência renovadas. Da Nova Zelândia para o mundo, como uma espécie de ginástica descartável, com a função de estímulo e incremento à venda, sateletizada pelo alto a partir da propaganda $\mathrm{e}$ marketing globais, entra em cena a inovação estética, que é justamente o processo de renovação que se desenvolve a serviço do domínio sensível sobre as pessoas a ser exercido pela aparência das mercadorias, neste caso, das práticas corporais. Assim, com uma função de venda, a aparência, a se insere na dinâmica de produção dos programas conferindo-lhes maior atratividade.

Tal processo é combinado ainda com a segmentação dos programas, conferindo-lhes forma ginástica peculiares, adequandoos aos estilos de vida, sempre em busca de ofertas originais que revigorem seu poder de atração sobre os variados nichos de consumo (ORTIZ, 1994). Sustentando-se nos princípios gerais da ginástica, todavia, conferindo-lhe uma roupagem nova, com sequenciamentos técnicos, cores, linguagem e musicalidade igualmente novos, sua atratividade ou valor de troca está relacionada com a corpolatria ${ }^{8}$. Neste contexto, a estrutura das pré-coreografias está intimamente ligada a uma música, que dita qual a próxima sessão de movimentos, mas que não deixa de seguir a lógica sequencial do aquecimento, parte principal e volta a calma.

O objetivo da Les Mills é criar experiências
inesquecíveis que mudem a vida das pessoas, a toda
hora e em qualquer lugar, e a música tem um papel
fundamental no nosso sistema. A música dirige
nossos programas, a coreografia, a maneira como

${ }^{8}$ A corpolatria, segundo Codo e Sene (1985), refere-se ao processo que, já na década de 1980 , entre a classe média, transformava os hábitos relativos aos cuidados com o corpo em obsessão, uma verdadeira idolatria, uma patologia psico-social com fortes traços de individualismo, narcisismo e hedonismo.

Movimento, Porto Alegre, v. 16, n. 04, p. 169-189, outubro/dezembro de 2010. 
nos movemos, a intensidade que colocamos em cada exercício, a maneira como usamos o Coaching... enfim, tudo. A música é nosso coração! A música tem um grande apelo emocional para nós. Ela é o foco de cada sessão?.

Senão vejamos como se estrutura uma sessão:

Coreografia e Música: Música 1 - Aquecimento e soltura; Música 2 - Início do trabalho cardiovascular e $1^{\circ}$ contato com a bola; Música 3 - Dança cardio; Música 4 - Cardio interativo; Música 5 - Pico cardio; Música 6 - Recuperação (Tai Chi \& Yoga); Música 7 - Equilíbrio e força de perna; Música 8 - Força funcional de membros superiores; Música 9 - Força funcional do quadril e musculatura dos glúteos; Música 10 - Força funcional do centro (abdominal); Música 11 - Força funcional do paravertebral; Música 12 - Alongamento e relaxamento ${ }^{10}$.

A despeito da permanente inovação, não se percebem mudanças significativas - tampouco revolucionárias - nas pré-coregrafias da Les Mills, visto que a estrutura e a finalidade das aulas refletem o que há de fundamental em qualquer aula de ginástica ${ }^{11}$. O que fica evidente no que diz respeito às diferenças, é quando se trata da função do professor. Desde a antiga calistenia ${ }^{12}$, esse é a figura central do processo pedagógico. Já no sistema Body Systems, tendo em vista a proposta de oferecer "um único modelo de ginástica, com

${ }^{9}$ Extrato de texto retirado da apostila, ou notas de coreografia, do Curso Body Vive ministrado durante a 5ํㅡㄹ Convenção Saúde Sport e Fitness, realizada em Goiânia, em março de 2008.

${ }^{10}$ Extrato de texto igualmente retirado da apostila, ou notas de coreografia, do Curso Body Vive ministrado durante a $5^{\circ}$ Convenção Saúde Sport e Fitness, realizada em Goiânia, em março de 2008. Para saber mais sobre o papel motivacional da música no programa Body Systems, ver Moura et al (2007).

${ }^{11}$ As mudanças vividas pela ginástica lhe agregaram novas bases, no entanto, sem alterações significativas na sistematização de seu conteúdo e forma, organizando-se a partir da seguinte estrutura: aquecimento - momento de "despertar o corpo" por exercícios aeróbicos que trabalham com a massa corpórea como um todo, podendo ser subdividido em duas fases, geral e específica; parte principal - momento de trabalhar com resistência cardiorespiratória e o sistema neuromuscular; e, volta à calma - permite a redução da freqüência cardíaca próximo aos valores de repouso, melhora o retorno venoso, remoção mais rápida do lactato, os exercícios geralmente envolvem a respiração e alongamento (NUOMURA; NISTA-PICOLLO, 2005).

${ }^{12} \mathrm{Um}$ sistema de ginástica que apresenta como característica a predominância de formas analíticas, a divisão dos exercícios em grupos, a associação da música ao ritmo dos movimentos a predominância dos movimentos sobre as posições e exercícios a mão livre como também com pequenos aparelhos como halteres e bastões (MARINHO, 1980).

Movimento, Porto Alegre, v. 16, n. 04, p. 169-189, outubro/dezembro de 2010. 
marca, identidade visual, músicas e projeto de marketing, próprios das academias que aderirem ao programa na forma de franquia" (PINHEIRO; PINHEIRO, 2006, p. 14), bem como pelos treinamentos rápidos com qualificação para o trabalho com produtos padronizados, o professor abandona sua autonomia, e com ela sua capacidade criativa, subordinando-se a condição de reprodutor de sequiências de pré-coreografias produzidas e distribuídas em escala mundial.

\section{A DOCÊNCIA ESVAZIADA}

Ao professor de Educação Física, para ser credenciado junto ao Body Systems, além de experiência com ginástica de academia, é exigido um elevado nível de treino corporal. Para se tornar certificado pelo sistema, o professor é avaliado por uma comissão e, obtendo aprovação, torna-se instrutor nacional, apto para trabalhar junto a qualquer uma das academias franqueadas. Para o credenciamento, o professor deve realizar uma formação inicial e, em seguida, um curso modular voltado a um dos programas do sistema. O material didático do professor é composto por manual, CD contendo as músicas do mix e DVD com a aula e notas de coreografia. O professor só pode ministrar aulas após ter concluído, com aprovação, os módulos do curso. Posteriormente, tem o prazo de até sessenta dias para enviar uma gravação em vídeo de sua aula para avaliação e, em caso de aprovação, terá direito ao certificado de validade internacional. Vale registrar que a inovação trimestral dos programas demanda um novo ciclo de capacitação, por sua vez, gerando novos custos para o professor.

A divisão do trabalho interna ao sistema de treinamento, o Body Training Systems, apresenta as seguintes nomenclaturas de desígnio para as categorias de professores e suas respectivas funções: Treinadores Pro - são os professores de Educação Física que atuam diretamente na formação dos professores do Sistema, responsáveis diretos pela divulgação dos programas Les Mills e Body Systems através dos treinamentos e aulas dadas nos workshops e nas Convenções de Fitness em que o Sistema participa; Avaliadores:

Movimento, Porto Alegre, v. 16, n. 04, p. 169-189, outubro/dezembro de 2010. 
são os responsáveis pelo credenciamento de novos professores, o que corresponde ao controle de qualidade do Sistema; Professores Especiais: são auxiliares dos Treinadores Pro. São graduados ou estudantes de Educação Física, e neste caso não atuam diretamente na área técnica, conforme a regulamentação da profissão estabelecida pelo Conselho Federal de Educação Física; e, Q-Pro: são professores de Educação Física em sua etapa final de preparação para tornarem-se Treinadores $\operatorname{Pro}^{13}$.

A Les Mills e a Body Systems exigem dos professores credenciados um conjunto de competências as quais seus Treinadores Pro chamam de "instruções para o sucesso". A primeira delas é capacidade de execução da pré-coreografia, a qual deve ser realizada com segurança, eficiência e motivação.

\begin{abstract}
A segurança se refere a capacidade do professor de decorar a coreografia e demonstrar que sabe o que está fazendo e falando; a eficiência diz respeito a perfeita execução e performance dos movimentos, pois o professor deve ser um exemplo; e a motivação relaciona-se a habilidade de levar o aluno a sentir prazer, sentir-se bem, alegre e feliz durante a aula, pois isso o fará voltar na próxima aula. Sem isso o professor não estará preparado para dar uma boa aula. (Treinador Pro 1).
\end{abstract}

A segunda relaciona-se com a técnica, ou seja, a execução dos movimentos e com a postura, pois o professor é considerado como um exemplo. Ele deve também possuir competências relativas ao coaching, isto é, ser um bom comunicador no sentido da orientação e motivação: "O professor não pode ter aquele corpo obeso, deformado, tem que malhar estar em forma e não errar durante a aula. Ele é o exemplo! Deve ainda fazer com que seu aluno alcance o seu objetivo, para tanto, deve se preparar, acompanhando e motivando o seu aluno." (Treinador Pro 1).

${ }^{13}$ Informações constantes da página web da Body Systems do Brasil. Disponível em: http:// www.bodysystems.net/. Acesso em 2 jun. 2008.

Movimento, Porto Alegre, v. 16, n. 04, p. 169-189, outubro/dezembro de 2010. 
A conexão e o entretenimento constituem outras competências exigidas, pois se espera do professor a habilidade para criar laços de afetividade, forjando relacionamentos com e entre os alunos.

\begin{abstract}
Somos uma tribo, uma família, e hoje as pessoas estão carentes. Então nós professores precisamos estar atentos a isso, e elogiarmos, presentearmos, estarmos sempre alegres e sorridentes, motivando nossos alunos. É o que faz a diferença nas aulas, momento de criar expressões de elogio e que faça os alunos se sentirem melhores, por exemplo: Vocês são demais! Abre o peito, abre o coração e deixa a emoção contagiar! É o momento de sentir a música e deixar relaxar! (Treinador Pro 2).
\end{abstract}

No que diz respeito às relações pedagógicas subjacentes a organização do trabalho interna proposta pelo Sistema, há uma perda de autonomia quanto ao papel docente dos professores, que assumem a função de reprodutores de um programa preestabelecido, que substitui o trabalho educativo, limitando sua interferência na rotina de exercícios pré-coreografados. As tecnologias de informação e comunicação substituem o papel docente dos professores, tornando seu trabalho rígido e acrítico, restringindo a ação diretiva relacionada ao planejamento do trabalho a ser realizado.

Sua atividade está centrada na execução e nas advertências de ritmo e correções durante a sessão, estimulando, corrigindo e animando os alunos. Ao ganhar tal atribuição, seja executando a coreografia com segurança e eficiência, seja ecoando frases feitas para a motivação dos alunos, seu trabalho é esvaziado de criatividade e conteúdo verdadeiramente significativo.

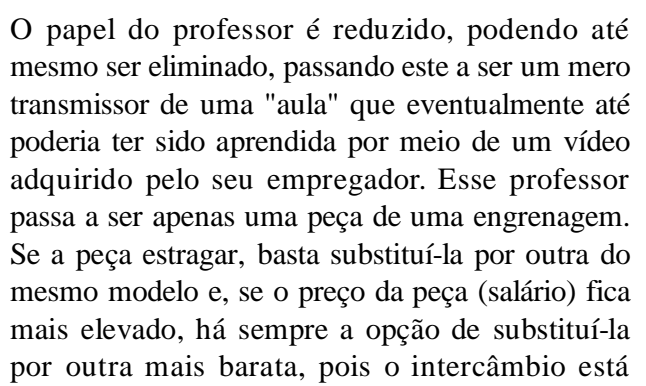

Movimento, Porto Alegre, v. 16, n. 04, p. 169-189, outubro/dezembro de 2010. 


\begin{abstract}
assegurado. As próprias empresas salientam esse aspecto nos materiais destinados aos proprietários de academias: "é fundamental poder substituir profissionais nos momentos de ausência dos titulares, como férias, faltas e outras ocorrências, sem que isso ocasione a insatisfação dos clientes". Indubitavelmente essa flexibilidade, também presente na mesa de negociações que envolvem questões salariais e alterações nas jornadas de trabalho, fragiliza o profissional empregado perante o empregador. (PINHEIRO; PINHEIRO, 2006, p. 17-18)
\end{abstract}

O trabalho do professor de Educação Física poder então ser caracterizado no interior do Sistema Body Systems como uma atividade que opõe o trabalho intelectual ao trabalho manual, com o professor se apresentando como retransmissor de programas de ginástica de grupo pré-coreografada independentes da academia e localidade. Ante as aparentes vantagens de menor dispêndio de tempo para a preparação das sessões, aproveitamento da mesma coreografia em várias aulas e academias, o treinamento único que confere credencial para atuação em várias academias, ampliando as oportunidades de emprego, o Sistema submete o professor a dependência de um fluxo contínuo de treinamento sob suas expensas - sob pena de perder o credenciamento -, a um maior risco de substituição e a redução do espaço para o exercício de sua autonomia intelectual e pedagógica. Segundo Furtado (2007, p.318), as possibilidades de um trabalho criativo e realizador são obliterados pelos princípios de gestão adotados pelas academias. "A divisão do trabalho encontrada entre os professores e avaliadores também impede que a concepção do trabalho seja oriunda do próprio professor".

Como prática profissional, a docência do professor de Educação Física possui natureza própria que advém da inter-relação entre a teoria e a prática, inteiramente articulada ao saber e ao fazer por meio da intervenção educativa no âmbito das práticas corporais, da ginástica, dos esportes, das lutas, do jogo, da dança, dentre outras, seja na academia, na escola, na praça, no clube, nos diversos campos de atuação profissional. Ocorre que, como trabalhador assalariado,

Movimento, Porto Alegre, v. 16, n. 04, p. 169-189, outubro/dezembro de 2010. 
o professor encontra-se sujeito ao processo de proletarização, o que se constata pela flexibilização do contrato de trabalho, excesso de jornada, doenças do trabalho, desproteção social etc. Por sua vez, as características da divisão social do trabalho migram para o fazer pedagógico, gerando a perda do controle do meio de produção de seu trabalho ${ }^{14}$, bem como a organização e planejamento de sua atividade, o que, para Enguita, (1991) opõe-se ao profissionalismo docente.

O professor passa a ser considerado um mero técnico reprodutor de conhecimentos e, no caso desse estudo, um instrutor de programas pré-elaborados por "especialistas", Assim, a docência, que se constitui como base da formação e um dos elementos da profissionalização, esvazia-se. É no exercício da docência que o professor exerce sua autonomia, realizando a seleção, organização e pedagogização dos conhecimentos e práticas que dizem respeito à cultura corporal. Por outro lado, o exercício da autonomia implica em saberes profissionais e em um processo formativo contínuo que demanda compreender como esses conhecimentos e práticas são produzidos, integrados, utilizados e tratados na prática profissional. Nesse sentido, a docência é compreendida como um ofício pleno de saberes construídos e reconstruídos no exercício da profissão. $\mathrm{O}$ afastamento do professo de Educação Física das funções de conceber, planejar e avaliar sua prática pedagógica resulta em uma docência esvaziada de sentidos e significados, impondo fortes limites a sua autonomia, isto é, a sua capacidade de diagnosticar contextos para exercer, com competência técnica e política, o trabalho pedagógico para com as práticas corporais, neste particular, a ginástica.

\footnotetext{
14"Investimentos mais elevados foram surgindo nos últimos anos na construção de academias de ginástica. Assim, o capital necessário para o início do negocio se eleva, dificultando o surgimento de novas academias por parte do professor de Educação Física". (FURTADO, 2007 , p. 59). Em outros termos, é cada vez mais recorrente a inserção subordinada do professor de Educação Física na cadeia produtiva do fitness, quando a os altos investimentos necessários, limitam as possibilidades de que este venha a controlar o meio de produção trabalho, na qualidade de proprietário ou gestor da academia.
}

Movimento, Porto Alegre, v. 16, n. 04, p. 169-189, outubro/dezembro de 2010. 


\section{Conclusão}

Os investimentos crescentes requeridos por parte das academias de ginástica reforçam as tendências de concentração e centralização, processo decorrente de fatores como concorrência, acesso ao crédito, incorporações, fusões etc. Ocorre que o processo de modernização de um mercado até então tradicional, o mercado de academias de ginástica, revela-se cada vez mais dependente de fatores como a inovação. Não há alternativa diante da competitividade estimulada pelo desenvolvimento do setor, bem como solução possível ante o crescimento vegetativo que apanha várias academias, limitando a expansão ou determinando a mortalidade do negócio.

Assim, no sentido de se diferenciarem e se consolidarem num mercado altamente competitivo, as academias de ginástica precisam constantemente buscar novos meios ou acrescentar algo novo em seus serviços e produtos para que os consumidores se sintam mais atraídos. Como um dos grandes desafios colocados para as academias diz respeito à superação da evasão, o que demanda tanto a atração de novos consumidores como na retenção e adesão daqueles já conquistados, verifica-se a redução planejada do ciclo de vida útil das práticas ofertadas e conseqüente lançamento de novas práticas, neste caso, os programas de ginástica que são constantemente renovados sob uma aparência estética, ritmo e coreografia igualmente renovados. Somada à obsolescência trimestralmente planejada de seus mixes e programas, a Body Systems adapta ainda seu produto às tendências de segmentação do consumo, com a diversificação de programas dirigidos a variados nichos e estilos de vida, garantindolhes atratividade diferenciada.

Considerando, então, a necessidade de inovação e sustentação da competitividade, a introdução do sistema de franquias e das novas tecnologias de informação e comunicação na produção e distribuição dos programas de ginástica da Body Systems configura-se também como um processo de transposição para a organização do trabalho pedagógico interno às academias de ginástica de um modelo de inovação característico do sistema empresarial que, até então, era

Movimento, Porto Alegre, v. 16, n. 04, p. 169-189, outubro/dezembro de 2010. 
aplicado a outros serviços e tipos de negócio. Os princípios da Body Systems, assentados sobre a racionalidade, eficiência e produtividade, por meio da fragmentação do trabalho, introduzindo elementos pedagógicos e didáticos tecnicistas no ambiente das academias.

Tais elementos se evidenciam pela ênfase na utilização de recursos audiovisuais na formação e avaliação dos professores credenciados pelo sistema, pelo desenvolvimento de componentes de instrução programada - o que envolve cursos de iniciação ao fitness, cursos modulares de capacitação para os programas, workshops trimestrais, convenções, aulas especiais, palestras etc -, pela avaliação periódica visando verificar e mensurar o atendimento dos objetivos previamente elaborados, as chamadas "instruções para o sucesso" - quais sejam: capacidade de execução da pré-coreografia, a técnica, ao coaching, a conexão e o entretenimento -, bem como pela separação entre os que planejam e avaliam - os treinadores pro e avaliadores do Body Training Systems - e os que reproduzem e executam as pré-coreografias - os professores credenciados pelo sistema empregados pelas academias -, com a consequente fragmentação do processo pedagógico.

O que assistimos, portanto, é um sofisticado processo de reconfiguração da organização do trabalho no setor de negócios que envolvem as academias de ginástica. Neste contexto, o caso Body Systems é emblemático das múltiplas dimensões: primeiro, a inovação do produto, com seus mixes de ginástica pré-coreografada; segundo, a gestão, com a incorporação dos princípios organização flexível do trabalho; terceiro, a forma de comercialização, com a implantação do sistema de franquia; e, por fim, a concepção de um novo modelo de negócios ajustado a realidade dos mercados globalizados, conforme destacam Pinheiro e Pinheiro (2006, p.19-20):

[...] envolvendo o franqueador internacional, o franqueador nacional, as indústrias de marcas associadas aos mais variados produtos e acessórios, bem como produtores de equipamentos dedicados, todos disputando clientes globais. Adicionalmente, modificam-se os antigos papéis e o relacionamento entre a administração das academias, os professores e os alunos.

Movimento, Porto Alegre, v. 16, n. 04, p. 169-189, outubro/dezembro de 2010. 
The fitness industry, the commodification of body practice and work of professor of physical education: the case of body systems

Abstract: This research seeks to examine the management processes and trends of innovation inherent in the development of "Fitness Industry", with special attention to the franchise system, and assess the implications of this system to the work of physical education teacher. It is organized from the literature review, desk research and field research based on the study of the system propagated by Body Systems, which involves the streamlining and standardization of production techniques and distribution programs for gymnastics group. Concludes that the system impacts the organization's internal work to academies, both in the form of marketing as the design of a new management model, disqualifying the activity of the physical education teacher.

Keywords: Physical education. Fitness Centers. Practice Management. Work.

La industria del fitness, la mercantilización de
las prácticas corporales y el trabajo de profesor
de educacion fisica: el caso body systems
Resumen: Esta investigación tiene por objeto exami-
nar los procesos de gestión de la innovación y las
tendencias inherentes al desarrollo de la "industria del
fitness", con especial atención al sistema de franquicia,
y evaluar las implicaciones de este sistema a la labor
del profesor de educación física. Está organizado de
la revisión de la literatura, investigación documental y
de campo basado en el estudio del sistema propaga-
da por sistema Body Systems, que implica la
simplificación y estandarización de técnicas de
producción y distribución de programas de la gimnasia.
Concluye que el sistema de impactos de trabajo inter-
no de la organización a las academias, tanto en la
forma de comercialización como el diseño de un nuevo
modelo de gestión, descalificar la actividad del profesor
de educación física.
Palabras clave: Educación Física. Centros de acon-
dicionamento. Gestión de la Práctica Profesional.
Trabajo.

Movimento, Porto Alegre, v. 16, n. 04, p. 169-189, outubro/dezembro de 2010. 


\section{REFERÊNCIAS}

ADORNO, Theodor Wiesengrund; HORKHEIMER, Max. A indústria cultural: o esclarecimento como mistificação das massas. In: Dialética do esclarecimento: fragmentos filosóficos. Rio de Janeiro: Jorge Zahar, 1985. p. 113-156.

BOGDAN, Robert; BIKLEN, Sari Knopp. Investigação qualitativa em educação. Porto: Porto, 1994.

BRAUNER, Vera Lúcia Pereira. Novos sistemas de aulas de ginástica: procedimentos didáticos (?) na formação dos professores. Revista Brasileira de Ciências do Esporte, Campinas, v. 28, n. 2, p. 211-219, 2007.

CODO, Wanderley; SENNE, Wilson. O que é corpolatria. São Paulo: Brasiliense, 1985

ENGUITA, Mariano Fernández. A ambigüidade da docência: entre o profissionalismo e a proletarização. Revista Teoria e Educação, Porto Alegre, n.4, p.41-61, 1991.

FURTADO, Roberto Pereira. Novas tecnologias e novas formas de organização do trabalho do professor nas academias de ginástica. Pensar a Prática, Goiânia, v. 10, n. 2, p. 307-322, 2007.

HAUG, Wolfgang Fritz. Crítica da estética da mercadoria. São Paulo: UNESP, 1997.

HARVEY, David. Condição pós-moderna. São Paulo: Loyola, 1998.

HELOANI, Roberto. Gestão e organização no capitalismo globalizado: historia da manipulação psicológica no mundo do trabalho. São Paulo: Atlas, 2003.

MARINHO, Inezil Penna. História geral da educação física. 2. ed. São Paulo: CIA Brasil, 1980.

MOURA, Nicole Lopes et al. A influência motivacional da música em mulheres praticantes de ginástica de academia. Revista Mackenzie de Educação Física e Esporte, São Paulo, v. 6, n. 3, p 103-118, 2007

NUOMURA, Myrian; NISTA-PICOLLO, Vilma L. Compreendendo a ginástica artística. São Paulo: Phorte, 2005.

ORTIZ, Renato. Mundialização e cultura. São Paulo: Brasiliense, 1994.

PINHEIRO, Ivan Antonio; PINHEIRO, Rodrigo Reska. Organização cientifica do trabaIho reinventa um mercado tradicional: o caso do fitness. RAE eletrônica, v. 5, n. 2 , p. 1-26, 2006.

SEVERINO, Antonio Joaquim. Metodologia do trabalho científico. 23 ed. São Paulo: Cortez, 2007.

Movimento, Porto Alegre, v. 16, n. 04, p. 169-189, outubro/dezembro de 2010. 
TOLEDO, Eliane de; PIRES, Fernanda Regina. Sorria! Marketing e consumo dos programas de ginástica de academias. Revista Brasileira de Ciência do Esporte, v. 29, n. 3, p. 41-56, 2008.

Financiamento: CnPQ-UFG

Recebido em: 04.07.2010

Aprovado em: 1.11.2010

Movimento, Porto Alegre, v. 16, n. 04, p. 169-189, outubro/dezembro de 2010. 